\title{
ASSESSING CLIMATE CHANGE LINKAGES RELATED TO WATER QUALITY TRADING EFFECTIVENESS FOR INCORPORATING ANCILLARY BENEFITS
}

\author{
JUHN-YUAN SU ${ }^{1}$, RAMESH GOEL ${ }^{1}$, STEVEN J. BURIAN ${ }^{1} \&$ MICHAEL E. BARBER ${ }^{1}$ \\ ${ }^{1}$ Civil and Environmental Engineering, University of Utah, Salt Lake City, UT, USA
}

\begin{abstract}
Climate change effect on water quality performance of lakes, rivers and streams is a significant concern for watershed planning and management. Climate change characteristics may potentially increase the likelihood that waterbodies will fail to meet established water quality standards, often obligating watershed managers to undertake expensive monitoring and load allocation studies for possible remedies against such impairment. One such load allocation study involves the implementation of water quality trading (WQT), which often is proposed as a mechanism for improving surface water quality goals under a socially and economically feasible manner. However, while future growth and land use change is incorporated through a margin of safety, WQT markets do not typically incorporate the characteristics of climate change that have been suggested to exhibit strong linkages against achieving the desired levels of water quality benefit. Consequently, this modelling study evaluates the characteristics of climate change upon the levels of water quality benefit along a river system subject to distinct load removal exercises: a) removal upon point sources only and b) removal based on a point-nonpoint source trading mechanism under a theoretical WQT program. This study applies such assessments upon the load allocation exercises through carbonaceous biochemical oxygen demand reduction for addressing a recognized dissolved oxygen problem along the Jordan River in Utah, conducting such analyses through selected climate change projections described by the representative concentration pathways. For achieving such tasks, separate simulations are conducted through the Water Quality Assessment Simulation Program, evaluating the performance of such trading mechanisms under observed meteorological data against modelled climate data through selected representative concentration pathway projections under a historical period from Water Year 2007 to 2009. This exercise assesses the performance of such load allocation studies subject to climatic characteristics toward suggesting linkages among climate change, water quality benefit and the effectiveness of a theoretical WQT mechanism.
\end{abstract}

Keywords: carbonaceous biochemical oxygen demand (CBOD), dissolved oxygen, total maximum daily load (TMDL), Water Quality Assessment Simulation Program (WASP).

\section{INTRODUCTION}

Water quality studies conducted over waterbodies throughout the United States are often centred around the Clean Water Act Section 303(d), requiring the monitoring of waterbodies for water quality performance based on the state-established water quality standards [1]. Consequently, any waterbody that appears to not meet such state-established water quality standards requires water quality monitoring and modelling assessment, along with load allocation studies planned for addressing such impairment. Typically, such monitoring and modelling studies over impaired waterbodies involve the implementation of a total maximum daily load study, conducting assessments of the waste-load allocations from point sources and the load allocations from nonpoint sources with adjustments for addressing uncertainties upon system performance through a margin of safety (MOS) [2]. The level of pollutant waste-load allocation and load allocation reductions conducted under total maximum daily loads for meeting state-established water quality goals are addressed through discharge permits, such as the National Pollutant Discharge Elimination System for point sources and/ or the Municipal Separate Storm Sewer System permits [3]. Meanwhile, one method for conducting and achieving pollutant reduction involves the concept of water quality trading 
(WQT), which is indicated as an innovative, cost-effective approach for addressing water quality standards [4]. Under the concept of WQT, pollutant reduction credits are purchased by a point/nonpoint source buyer through pollutant reduction applied upon other point/nonpoint sources within the same waterbody as the buyer for meeting water quality standards [4]. Such pollutant reduction credits, described through trade ratios, often involve significant collaborations among the point/nonpoint sources against any associated entities, possibly including state agencies and consulting firms [5]. While the derivation of trade ratios for pollutant reduction credit from a WQT program attempts addressing the waterbody impairment, MOS is often suggested to incorporate waterbody, along with land use, characteristics, such as those recommended by the Wisconsin Department of Natural Resources [6]. On the other hand, WQT programs typically appear to not incorporate the effects of futuristic conditions as MOS factors upon trade ratios, particularly climate change characteristics that often are suggested to exhibit linkages with water quality performance. Hence, this article conducts analyses of climate change characteristics on the performance of a trading mechanism toward suggesting a MOS for describing pollutant reduction credit.

\section{BACKGROUND}

\subsection{Climate change and water quality}

Climate change characteristics often effect the water quality performance of watersheds, particularly projecting increased nutrient loads and warmer water temperatures thus needing increased levels of removal required for achieving state-established standards. For instance, climate change characteristics suggest increases in phosphorus loadings due to changes in temperature followed by precipitation patterns [7], with increasing temperatures implicating increases in biochemical oxygen demand (BOD) loads [8]. Increases in BOD loads, which are suggested to be correlated with increased air temperature due to climate change with increased levels of urbanization, imply deteriorating dissolved oxygen (DO) levels, such as yielding DO concentrations below $2 \mathrm{mg} / \mathrm{L}$ by 2050 [9]. Furthermore, climate change characteristics are often found to suggest increasing levels of loading by nitrogen, phosphorus and suspended solids among several watersheds across the United States by 2050 , hence yielding adverse effects upon the water quality performance of several waterbodies [10]. Therefore, such increases in nutrient loadings due to climate change often precipitate the need for greater levels of pollutant removal for addressing established standards, with increased likelihood of violating such water quality standards for applying similar levels of removal for futuristic conditions as those implemented historically [11]. Hence, an assessment of climate change upon pollutant reduction credit attained through WQT appears recommended for suggesting MOS upon trade ratios due to climatic characteristics.

\subsection{Case study: Jordan River watershed in Salt Lake City, UT}

The Jordan River in Salt Lake City, Utah (UT) is an approximately 83-km (51-mile) reach originating as the outlet from a shallow freshwater lake (Utah Lake) flowing from north to south, discharging into the Great Salt Lake. This river system receives several inflows from tributaries, storm drains and wastewater treatment plants (WWTPs) and has several significant diversions that take water out of the river. Figure 1 provides an overview of the tributaries, storm drains, WWTPs and diversions along the Jordan River.

As indicated in Fig. 1, the Jordan River system receives several tributary inflows, storm drains, conduits, three WWTPs (South Valley, Central Valley discharging into Millcreek and 


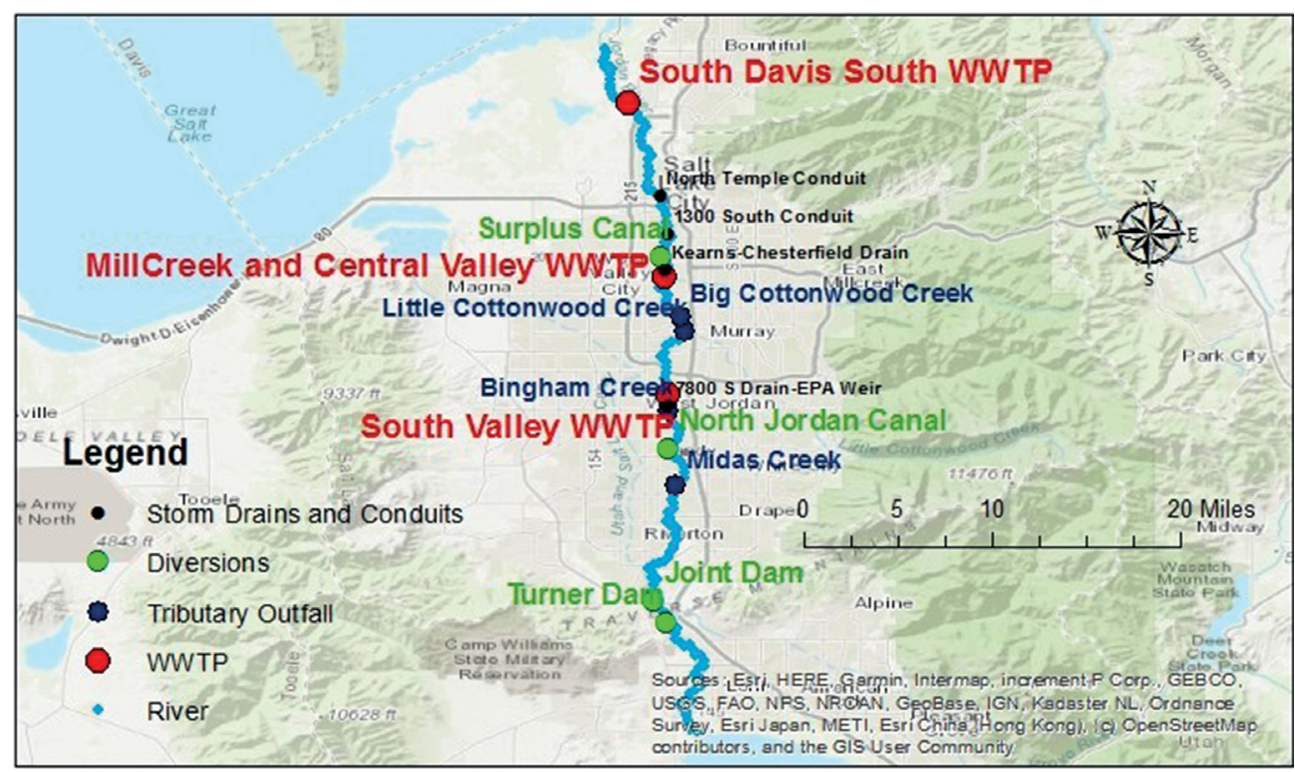

Figure 1: Jordan River system in Salt Lake City, UT, with corresponding tributary outfalls, storm drains, WWTPs and diversions.

South Davis South) and groundwater inflows along the reach. Meanwhile, the river system exhibits four locations that divert flow out of the Jordan River, involving Turner Dam located at approximately $16 \mathrm{~km}$ downstream from the effluent of the shallow freshwater lake, Joint Dam at approximately $2.5 \mathrm{~km}$ downstream from Turner Dam, the North Jordan Canal and the Surplus Canal at approximately $2 \mathrm{~km}$ downstream from Millcreek. Portions of the Jordan River system have been indicated as impaired due to water temperature and DO, particularly downstream of the Surplus Canal [12].

\section{DATA AND METHODOLOGY}

\subsection{Model simulations}

For this study, water quality models were developed for a river system using the Water Quality Assessment Simulation Program, Version 8 (WASP8), applying the advanced eutrophication module [13]. The water quality models focus primarily on simulating water temperature, DO and carbonaceous biochemical oxygen demand (CBOD) for assessing the applications of WQT on DO performance subject to CBOD pollutant removal over a 3-year timeframe (1 October 2006 to 30 September 2009).

\subsection{Data sources for meteorological data and modelled climate projection data}

Observed meteorological data were obtained for developing and calibrating the WASP river model and for simulating historical water quality conditions. The sources for historical observed meteorological data for the time period of interest (1 October 2006 to 30 September 2009) are documented in Table 1. 
Table 1: Sources of observed meteorological data and vegetative cover for topography and canopy shading over the WASP river model over 1 October 2006 to 30 September 2009.

\begin{tabular}{lll}
\hline Data Source & Site(s) Retrieved & Relevant Parameters \\
\hline $\begin{array}{l}\text { University of Utah } \\
\text { Mesowest Database }\end{array}$ & $\begin{array}{l}\text { Salt Lake International } \\
\text { Airport }\end{array}$ & $\begin{array}{l}\text { Air temperature, relative } \\
\text { humidity, wind speed, cloud } \\
\text { cover }\end{array}$ \\
SOLRAD FTP Database & $\begin{array}{l}\text { Salt Lake International } \\
\text { Airport } \\
\text { Riparian Vegetative Cover } \\
\text { Utah Division of Water }\end{array}$ & $\begin{array}{l}\text { Solar radiation } \\
\text { Quality (UDWQ) }\end{array}$ \\
\hline
\end{tabular}

Climate change characteristics described through the representative concentration pathways (RCPs) are assessed through the application of modelled climate data. The following climate change projections and the general descriptions of the data sources employed are as follows:

- RCP 4.5: This climate change projection with a radiative forcing of 4.5 watts per square meter employs the statistically downscaled daily climate data provided by the University of Idaho [14] derived through the Multiadaptive-Constructed Analogs [15]. Furthermore, due to the temporal resolution of the climate data, temporal disaggregation routines are applied for yielding sub-daily climate data through an open-source package MELODIST [16].

- RCP 6.0: This climate change projection with a radiative forcing of 6.0 watts per square meter implements the dynamically downscaled hourly climate data provided by the University of Utah Department of Atmospheric Sciences that applies the Community Climate Systems Model, Version 4 [17].

- RCP 8.5: This climate change projection with a radiative forcing of 8.5 watts per square meter applies the similar data sources and the temporal disaggregation routines as those for RCP 4.5.

\subsection{Data sources for inflows and diversions for the case study on the Jordan River}

The WASP river models allow the user to input headwater quantity and quality values that serve as the upstream boundary conditions for the system. The WASP models also allow the user to input inflow quantity and quality from tributary outfalls, WWTPs, storm drains and conduits, along with flow quantity being diverted out of the system. At the same time, the WASP models allow the user to define the levels of removal upon inflow quantity and quality for point sources (e.g., WWTPs) and nonpoint sources (e.g., tributaries, storm drains, conduits, etc.) through the implementation of four groups of CBOD: river/headwater BOD, WWTP BOD, tributary BOD and storm drain BOD. Table 2 documents the data sources for retrieving water temperature, CBOD and DO data, along with inflow/outflow quantity for populating the headwater, point sources, tributaries, storm drains/conduits and diversions for the Jordan River. In addition, groundwater quantity data have been implemented based on monthly groundwater discharge data provided by the Utah Division of Water Quality, with approximations implemented for populating groundwater quality into the river model [18]. 
Table 2: Sources of flow quantity/quality for headwater, WWTP, tributary, storm drains and diversions, with the agency for data source (UDWQ = Utah Division of Water Quality; UDWR = Utah Division of Water Rights; SLC = Salt Lake County), from most upstream to most downstream.

\begin{tabular}{|c|c|c|}
\hline $\begin{array}{l}\text { Headwater, WWTP, Creek, } \\
\text { Drain, Conduit, Diversion }\end{array}$ & $\begin{array}{l}\text { Data Employed (Site No., Discharge Monthly } \\
\text { Report (DMR), etc.) }\end{array}$ & $\begin{array}{l}\text { Agency } \\
\text { for Data }\end{array}$ \\
\hline Utah Lake effluent & 4994790 (Jordan R at Utah L Outlet U121 Xing) & UDWQ \\
\hline Turner Dam & $\begin{array}{l}\text { 05.01.07 (Jordan Valley Conservancy Dist), } \\
06.02 \text { (Utah \& Salt Lake Canal), } 06.01 \text { (Utah } \\
\text { Lake Distribution Canal (59-13)), } 06.03 \text { (East } \\
\text { Jordan Canal (Total)) }\end{array}$ & UDWR \\
\hline Joint Dam & $\begin{array}{l}07.01 \text { (Jordan \& Salt Lake Canal (SLC) (57- } \\
7624)), 07.02 \text { (South Jordan Canal (Total)) }\end{array}$ & UDWR \\
\hline Midas Creek & 4994420 (Butterfield/Midas Ck ab Jordan River) & UDWR \\
\hline North Jordan Canal & 10 (North Jordan Canal) & UDWR \\
\hline Bingham Creek & 4994190 (Bingham Ck at 1300 West) & UDWQ \\
\hline 7800 South Drain Quantity & $\begin{array}{l}\text { 05.01.07 (Jordan Valley Conservancy Dist), } \\
\text { 06.01 (Utah Lake Distributing Canal (59-14)) }\end{array}$ & UDWR \\
\hline 7800 South Drain Quality & $\begin{array}{l}4994170 \text { (Jordan at } 7800 \text { S Xing Ab S Valley } \\
\text { WWTP) }\end{array}$ & UDWQ \\
\hline South Valley WWTP & DMR & UDWQ \\
\hline Little Cottonwood Creek & $\begin{array}{l}290 \text { (Little Cottonwood Ck at } 300 \text { West) for } \\
\text { Quantity, } 4993580 \text { (Little Cottonwood Ck } 4900 \\
\text { S } 600 \text { W) for Quality }\end{array}$ & $\begin{array}{l}\text { SLC, } \\
\text { UDWQ }\end{array}$ \\
\hline Big Cottonwood Creek & $\begin{array}{l}390 \text { (Big Cottonwood Ck at } 300 \text { West) for } \\
\text { Quantity, } 4992970 \text { (Big Cottonwood Ck Ab } \\
\text { Jordan R @ 500 W 4200 S) for Quality }\end{array}$ & $\begin{array}{l}\text { SLC, } \\
\text { UDWQ }\end{array}$ \\
\hline $\begin{array}{l}\text { Millcreek (upstream of } \\
\text { Central Valley WWTP) }\end{array}$ & 490 (Mill Creek @ 460 West) for Quantity & SLC \\
\hline Central Valley WWTP & DMR for Quantity & UDWQ \\
\hline $\begin{array}{l}\text { Millcreek (downstream of } \\
\text { Central Valley WWTP) }\end{array}$ & $\begin{array}{l}4992480 \text { (Millcreek Ab Confl/Jordan River B1 } \\
\text { Central Valley WWTP Discharge) for Quality }\end{array}$ & UDWQ \\
\hline $\begin{array}{l}\text { Kearns-Chesterfield Drain } \\
\text { Quantity }\end{array}$ & $\begin{array}{l}07.02 \text { (South Jordan Canal (Total)), } 10 \text { (North } \\
\text { Jordan Canal (Total)) }\end{array}$ & UDWR \\
\hline $\begin{array}{l}\text { Kearns-Chesterfield Drain } \\
\text { Quality }\end{array}$ & 4992390 (Decker Pond Outflow Ab Jordan R) & UDWQ \\
\hline Surplus Canal & 17 (At 17th South) & UDWR \\
\hline $\begin{array}{l}1300 \text { South Conduit } \\
\text { Quantity }\end{array}$ & $\begin{array}{l}520 \text { (Parley's Ck), } 620 \text { (Emigration Ck at } \\
\text { Canyon Mouth), } 740 \text { (Red Butte Ck at } 1600 \text { E) }\end{array}$ & SLC \\
\hline 1300 South Conduit Quality & $\begin{array}{l}4992070 \text { (Jordan River at } 1300 \text { S Storm Sewer } \\
\text { Mouth) }\end{array}$ & UDWQ \\
\hline
\end{tabular}


Table 2: (Continued)

\begin{tabular}{lll}
\hline $\begin{array}{l}\text { Headwater, WWTP, Creek, } \\
\text { Drain, Conduit, Diversion }\end{array}$ & $\begin{array}{l}\text { Data Employed (Site No., Discharge Monthly } \\
\text { Report (DMR), etc.) }\end{array}$ & $\begin{array}{l}\text { Agency } \\
\text { for Data }\end{array}$ \\
\hline North Temple Conduit & $\begin{array}{l}820 \text { (City Ck at Memory Grove Park) for } \\
\text { Quantity, 4991920 (City Ck/North Temple } \\
\text { Conduit Ab Jordan R) for Quality }\end{array}$ & $\begin{array}{l}\text { SLC, } \\
\text { UDWQ }\end{array}$ \\
South Davis South WWTP & DMR & UDWQ \\
\hline
\end{tabular}

\subsection{Removal cases and WQT evaluation metrics}

The following removal scenarios are implemented for assessing the performance of a WQT mechanism:

- Removal upon WWTP sources only: All WWTPs along the river system model encounter a 95\% removal upon WWTP CBOD.

- Point-nonpoint source trading: As treatment processes tend to yield a BOD removal efficiency at approximately 85\% [19], the removal of 95\% upon WWTP CBOD appears rather infeasible. Hence, an example trading mechanism is applied for which all WWTPs encounter an $80 \%$ WWTP CBOD removal while the tributaries, storm drains and conduits exhibit a 50\% CBOD removal.

Such removal and example trading mechanisms are implemented for assessing the CBOD and DO performance subject to observed historical meteorological data followed by the distinct climate change RCP projections. In this investigation, the performance metrics of the example point-nonpoint source trading mechanism through calculating the level of benefit in concentration attained through the trading mechanism relative to the level of benefit under WWTP CBOD removal only. For instance, the ratio of the level of benefit for the trading mechanism relative to WWTP BOD removal only is derived through the following formulation for describing the level of benefit upon DO.

$$
R_{\mathrm{DO}}=\frac{[\mathrm{DO}]_{W Q T}-[\mathrm{DO}]_{N o}}{[\mathrm{DO}]_{W W T P}-[\mathrm{DO}]_{N o}}
$$

As indicated in Equation 1, the ratio $R_{\mathrm{DO}}$ is calculated based on the DO concentration by WQT at any river segment, $[\mathrm{DO}]_{W Q T}$, subtracted by the DO concentration under no removal applied, $[\mathrm{DO}]_{N o}$, divided by the DO concentration under WWTP CBOD removal only, $[\mathrm{DO}]_{W W T P}$, that is subtracted by $[\mathrm{DO}]_{N o}$. In other words, Equation 1 computes the level of increase upon the DO concentration attained through a trading mechanism relative to the increase for which only WWTP CBOD removal is applied. Meanwhile, a similar formulation can be derived for CBOD towards evaluating the level of CBOD removal attained through the trading mechanism relative to WWTP CBOD removal only.

$$
R_{\mathrm{CBOD}}=\frac{[\mathrm{CBOD}]_{N o}-[\mathrm{CBOD}]_{W Q T}}{[\mathrm{CBOD}]_{N o}-[\mathrm{CBOD}]_{W W T P}} .
$$


On the other hand, unlike Equation 1 that calculates the relative levels of DO benefit, Equation 2 computes the ratio for $\mathrm{CBOD}, R_{\mathrm{CBOD}}$, as the level of decrease in CBOD concentration through WQT by subtracting the CBOD concentration without removal, $[\mathrm{CBOD}]_{N o}$, by the concentration under WQT, $[\mathrm{CBOD}]_{W Q T}$, relative to the level of decrease upon the CBOD concentration under WWTP CBOD removal $\left([\mathrm{CBOD}]_{N o}-[\mathrm{CBOD}]_{W W T P}\right)$. For this exercise, Equations 1 and 2 are applied for deriving ratios per river segment per climate change projection, with separate ratios derived for the simulations that apply observed meteorological data. Then, the percentage difference upon the ratio derived per climate change RCP projection relative to the ratio derived from the simulations under observed historical meteorological data is computed through the following formulation.

$$
P_{R C P}=\left(\frac{X_{i, R C P}-X_{i, \text { Obs. }}}{X_{i, \text { Obs }}}\right) * 100 .
$$

As indicated in Equation 3, the percent difference of the results yielded by the RCP projection, $P_{R C P}$, is computed based on the parameter $X$, which can serve as the concentration or the ratio of WQT benefit derived from Equations 1 or 2, for constituent $i$ that can indicate either DO or CBOD yielded through a model run under an RCP projection, $X_{i, R C P}$, relative to the parameter $X$ (concentration, ratio of WQT benefit, etc.) for constituent $i$ (DO or CBOD) yielded by the simulations that implement observed historical meteorological data, $X_{i, \text { Obs. }}$. Hence, for this exercise, the removal and trading cases are implemented for all selected climate change projections, with Equations 1 to 3 applied for assessing the level of benefit attained through a WQT mechanism.

\section{RESULTS AND DISCUSSION}

\subsection{DO and BOD concentrations over the study time period}

For this exercise, the WASP model simulations and the removal cases are conducted upon the Jordan River over 3 water years (1 October 2006 to 30 September 2009). The DO and CBOD concentrations among the historical scenario that applies observed meteorological data are initially compared with those yielded by the climate change RCP scenarios for which no removal upon CBOD is applied. Then, ratios of CBOD and DO benefit for applying a trading mechanism are derived and compared along the distinct climate change RCP scenarios against the historical case. Figure 2 displays the DO and CBOD concentrations along segment JR117, which serves as a segment downstream of the Surplus Canal and hence intentionally selected for evaluating DO impairment, subject to distinct climate change projections.

Meanwhile, Figure 3 displays the ratios of CBOD and DO benefit attained through an example trading mechanism (e.g., 80\% WWTP CBOD removal, 50\% tributary + storm drain CBOD removal) relative to the corresponding CBOD and DO benefit under 95\% WWTP CBOD removal for segment JR117.

At the same time, the CBOD and DO longitudinal profile along the Jordan River are incorporated for comparing the performance among distinct historical and climate change scenarios, selecting a time period during the summer for which elevated temperatures and lower flows are observed. Figure 4 displays the CBOD and DO longitudinal profile along the Jordan River without any CBOD removal applied under 19 August 2009 at 3 PM. 


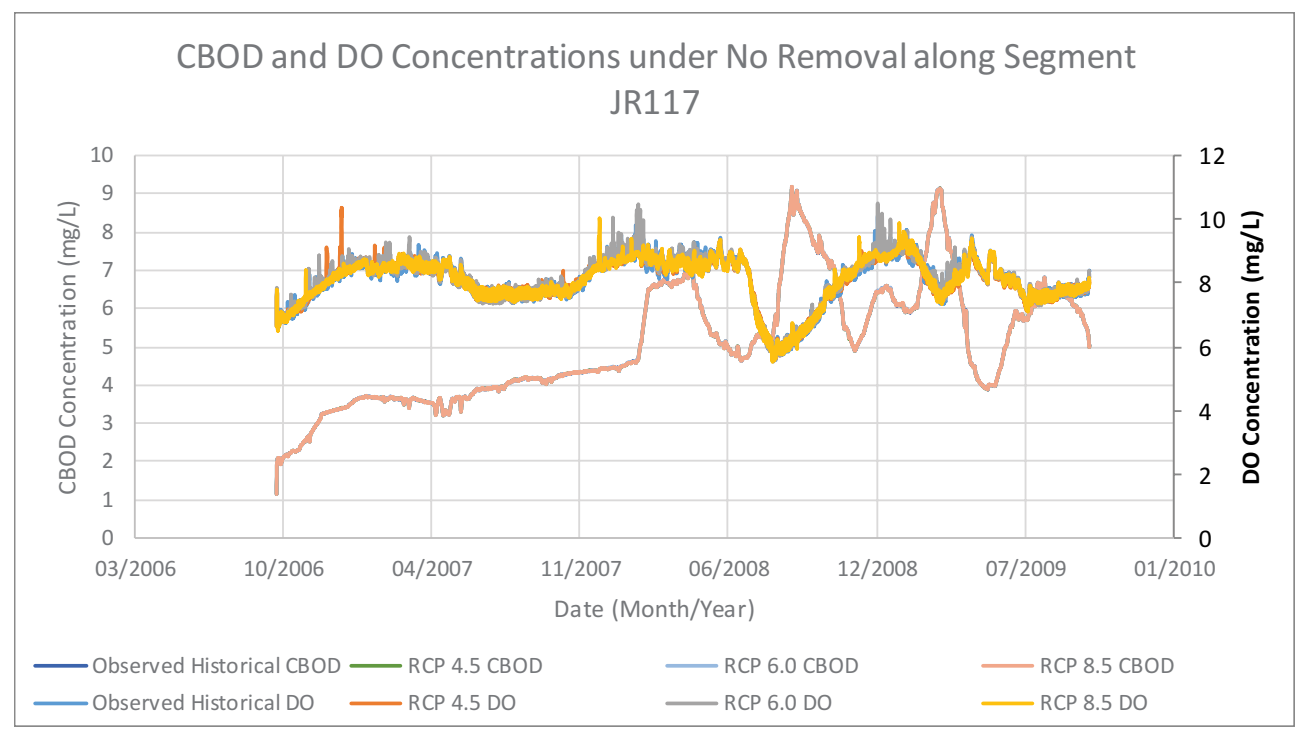

Figure 2: CBOD and DO concentrations along the Jordan River segment JR117 (1 km Downstream of Surplus Canal) under no CBOD removal from 1 October, 2006 to 30 September, 2009 under distinct historical and climate change RCP scenarios.

Furthermore, the following figures (Fig. 5) provide the Jordan River longitudinal profile up to the South Valley WWTP (41 km from downstream) at 19 August 2009 at 3 PM for displaying the ratio of CBOD and DO benefit for conducting the example trading mechanism relative to WWTP CBOD removal only and the percentage difference upon CBOD and DO ratio per climate change scenario as compared to the historical case.

\subsection{Effects of climate change characteristics upon DO/BOD concentrations in model}

Relative to the water quality concentrations yielded by the observed historical case (e.g., the implementation of observed meteorological data), the climate change RCP scenarios suggest greater effects upon the DO concentrations than those upon CBOD. For instance, the DO concentrations yielded by RCP 4.5, 6.0 and 8.5 appear to exhibit deviations as compared to the one by the observed historical case under no CBOD removal. Meanwhile, under no CBOD removal, RCP 8.5 appears to suggest lower DO concentrations relative to the observed historical case, exhibiting up to 10-15\% DO decrease along JR117 during the wintertime (e.g., December 2008). At the same time, the climate change RCP scenarios suggest decreases upon the DO concentration relative to the observed historical case (Fig. 4), particularly upstream of the South Valley WWTP (41 km from downstream) that yield up to $3 \%$ decrease. However, the climate change RCP scenarios appear to suggest minor changes upon the CBOD concentration relative to the observed historical case, yielding within $1 \%$ increase/decrease for both the time-series plot (Fig. 2) and the longitudinal profile (Fig. 4). Hence, the climate change RCP scenarios appear to suggest decreasing trends with DO and thus greater removal levels for CBOD for addressing state-established DO standards though further analyses appear recommended for evaluating such linkages. 
Ratio of Benefit upon CBOD among WQT vs. No Trading (WWTP Removal Only) for Segment JR117

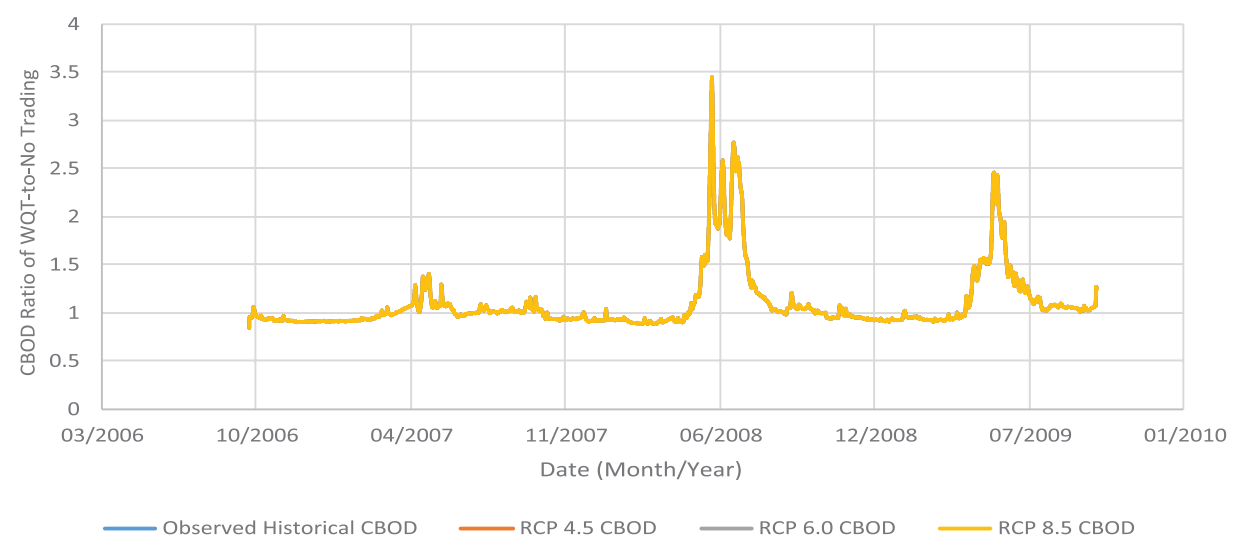

(a)

\section{Ratio of Benefit upon DO among WQT vs. No Trading (WWTP Removal Only) for Segment JR117}

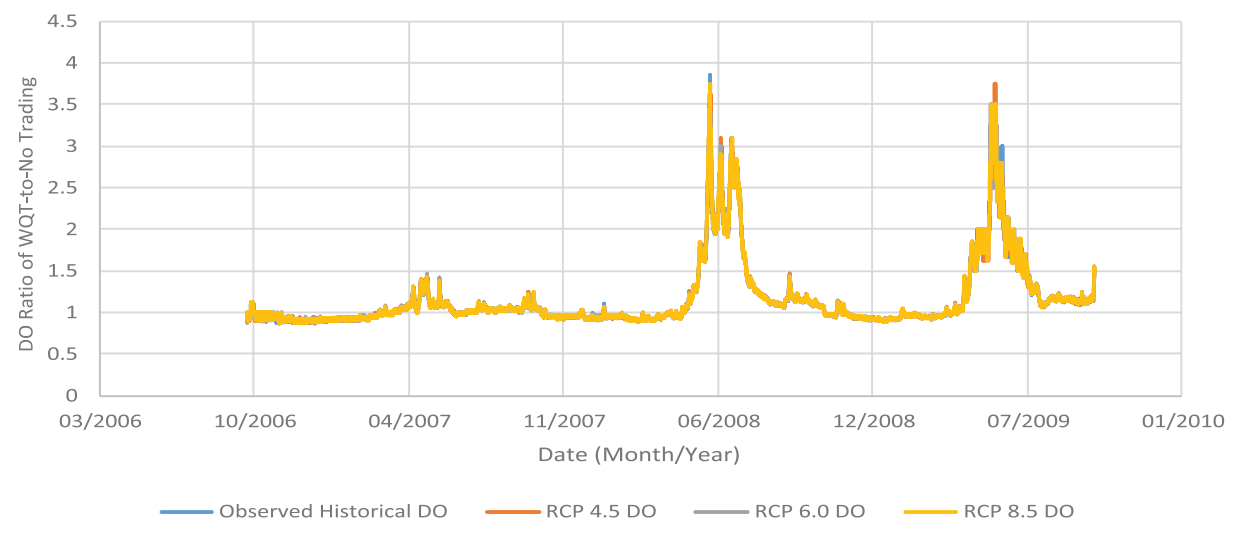

(b)

Figure 3: Ratio of benefit along the Jordan River segment JR117 (1 km downstream of Surplus Canal) under $80 \%$ WWTP $+50 \%$ tributary and storm drain CBOD removal against 95\% WWTP CBOD removal only from 1 October, 2006 to 30 September, 2009 under distinct historical and climate change RCP scenarios. (a) ratio of CBOD benefit; (b) ratio of DO benefit.

\subsection{Implications of climate change characteristics upon WQT}

The climate change RCP scenarios appear to yield similar levels of decrease upon the CBOD and increase upon the DO concentrations relative to the observed historical case among all removal cases (e.g., no removal, WWTP removal, trading). From the Jordan River longitudinal profile for 19 August, 2009 at 3 PM, the climate change RCP and the observed historical 


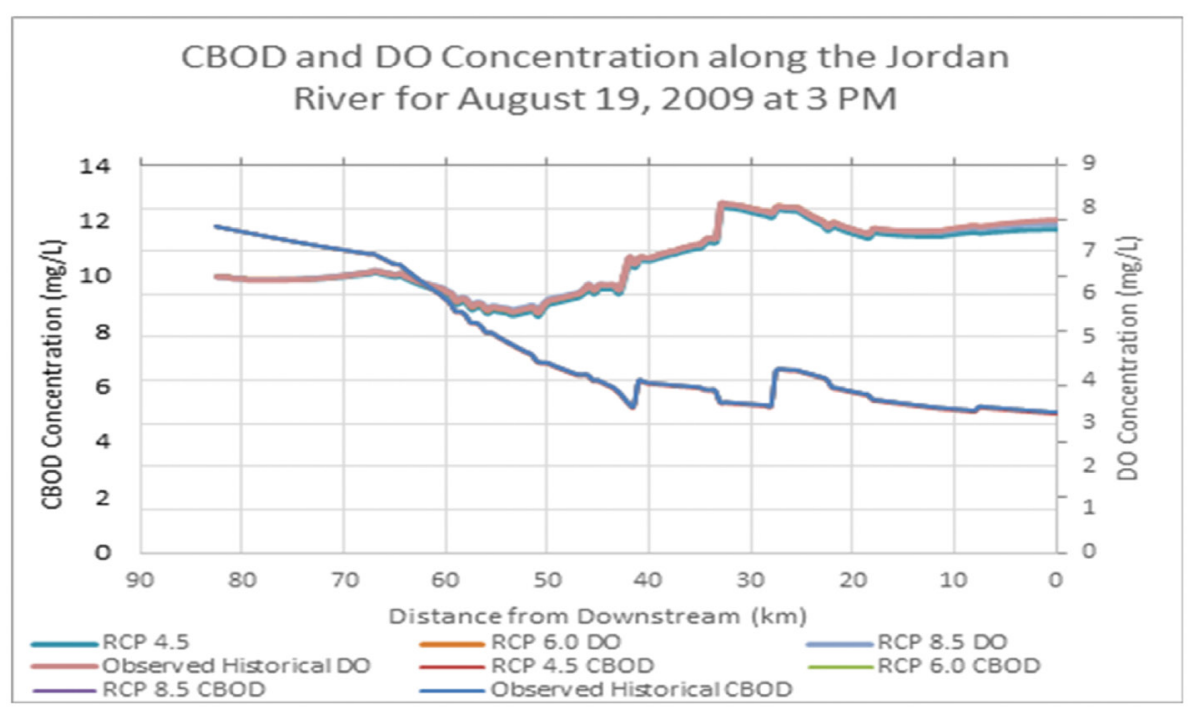

Figure 4: Longitudinal profile along the Jordan River for CBOD and DO on 19 August 2009 at 3 PM.

scenarios yield up to an approximate 50\% decrease upon CBOD along the Surplus Canal (25.5 $\mathrm{km}$ from downstream) and an approximate 1\% DO increase near the most downstream end (1-2 km from downstream). Meanwhile, the Jordan River longitudinal profiles yield ratios for CBOD and DO benefit greater than 1 among all climate change RCP and the observed historical scenarios, suggesting greater benefit attained through WQT than WWTP CBOD removal only. Furthermore, the ratios for CBOD and DO benefit appear greater than 1 during the summer months of the simulation among all RCP scenarios (Fig. 3), with values up to 3.5 for June 2008 and 2009. On the other hand, the ratios for CBOD and DO benefit among the climate change RCP scenarios appear similar to those yielded by the observed historical case, yielding within $1 \%$ difference in ratios. Such characteristics suggest the generally weak linkages among climate change RCP scenarios against the effectiveness of the example trading mechanism (e.g., 80\% WWTP + 50\% tributary/storm drain CBOD removal), recommending generally negligible margins of safety upon trade ratios due to climate change. However, since uniform CBOD loadings are applied among the climate change RCP and the observed historical cases for the exercise, further analyses appear recommended for deriving linkages among climate change and the effectiveness of WQT before such conclusions over such effects can be verified.

\section{CONCLUSIONS}

Water quality simulations were conducted on a river system under distinct climate change scenarios for evaluating the effects upon the water quality performance followed by the effectiveness of WQT. Such evaluations were conducted for suggesting potential margins of safety upon trade ratios for describing pollutant reduction credit attained through WQT due to climatic characteristics. While the analyses conducted over a river system suggest generally weak effects of climate change upon the effectiveness of WQT, the evaluations appear to 


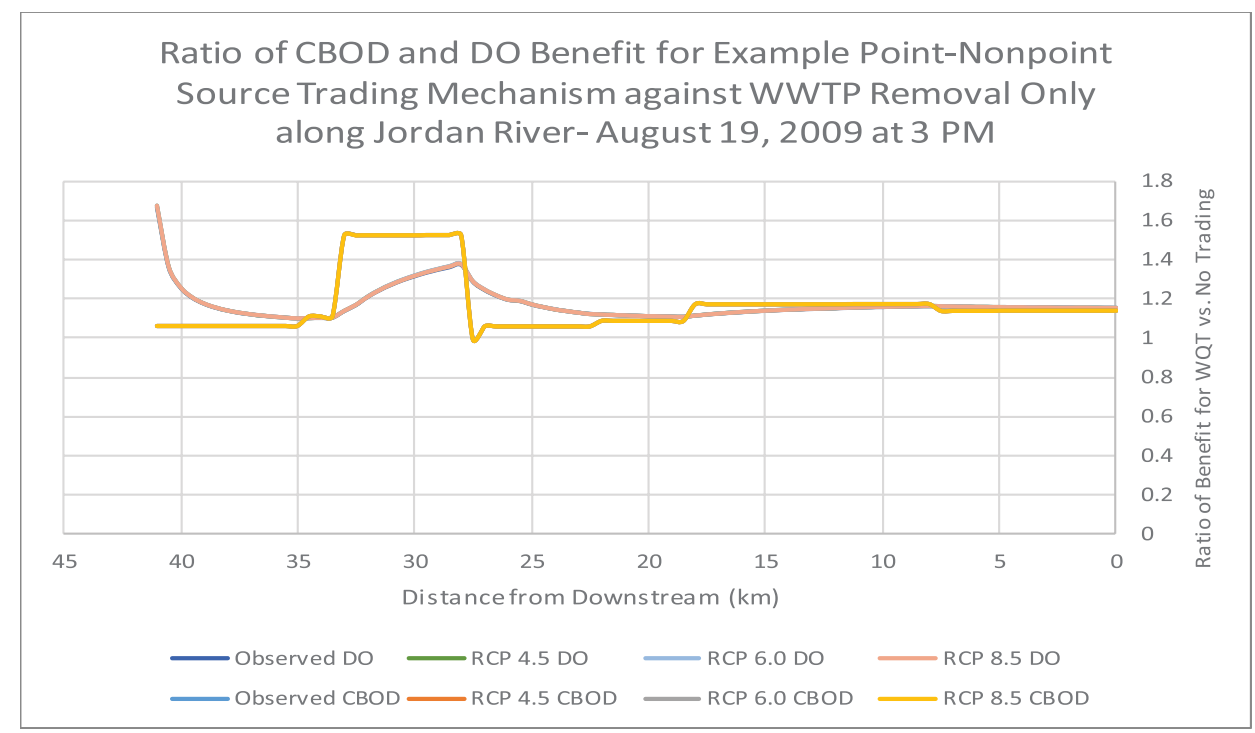

(a)

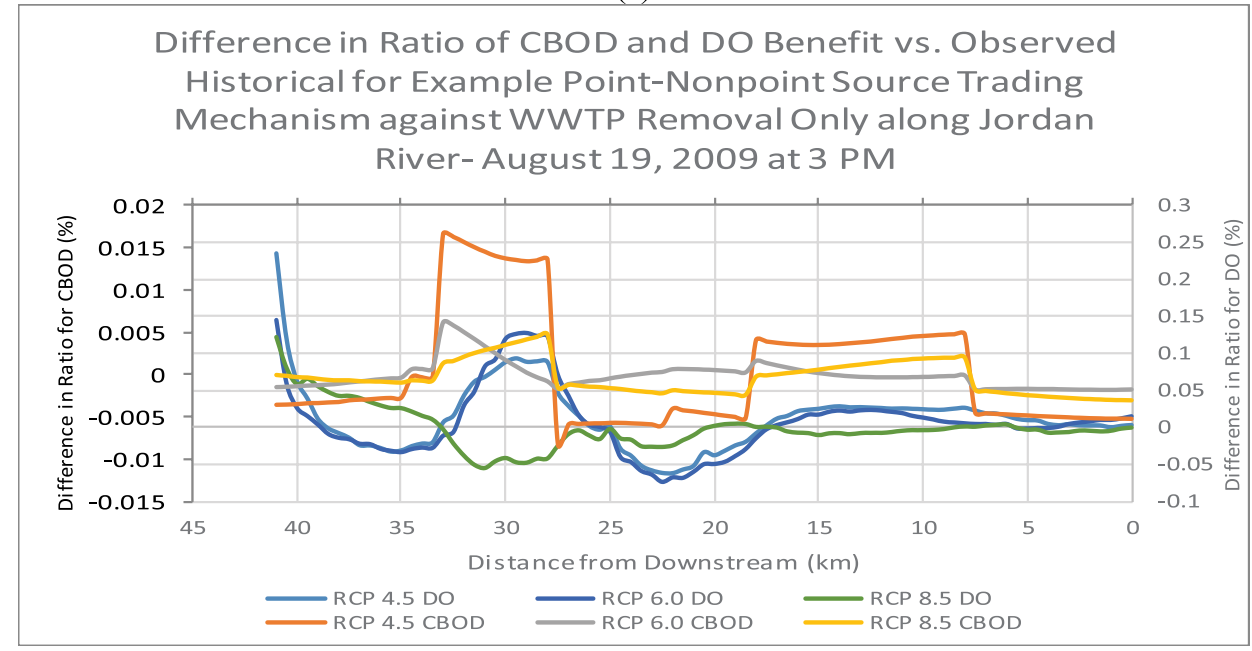

(b)

Figure 5: CBOD and DO benefit along the Jordan River longitudinal profile for 19 August, 2009 at 3 PM under $80 \%$ WWTP $+50 \%$ tributary and storm drain CBOD removal relative to 95\% WWTP CBOD removal. (a) Ratio of benefit per climate change RCP and observed historical scenario; (b) percent difference in ratio per climate change RCP relative to the observed historical case.

indicate potential linkages among climate change and the water quality performance. On the other hand, such analyses of climate change, water quality and WQT require further assessment regarding the climate change data sources, the effects upon the water quality loadings and many other salient factors before such linkages can be derived. 


\section{ACKNOWLEDGEMENTS}

The authors would like to thank the Utah Department of Environmental Quality for processing and providing the inflow quantity and quality data. Funding for this project was provided as part of the University of Utah's Project Number 835866-01 funded by the U.S. Environmental Protection Agency (EPA). This work has not been formally reviewed by EPA. The views expressed in this document are solely those of the authors and do not necessarily represent those of the agency. EPA does not endorse any products or commercial services mentioned in this publication.

\section{REFERENCES}

[1] Smith, E.P., Ye, K., Hughes, C., \& Shabman, L. Statistical assessments of violations of water quality standards under Section 303(d) of the Clean Water Act. Environmental Science \& Technology, 35(3), pp. 606-612, 2001.

[2] U.S. E.P.A. Protocol for Developing Nutrient TMDLs, First Edition, Office of Water (4503F), EPA 841-B-99-007, Washington, D.C., 1999.

[3] Ribaudo, M.O. \& Gottlieb, J. Point-nonpoint trading - can it work? Journal of the American Water Resources Association (JAWRA), 47(1), pp. 5-14, 2011.

[4] U.S. E.P.A. Water Quality Trading Toolkit for Permit Writers. Office of Wastewater Management, EPA 833-R-07-004, Washington, D.C., 2009.

[5] Woodward, R.T., Kaiser, R.A., \& Wicks, A.-M. B. The structure and practice of water quality trading markets. Journal of the American Water Resources Association (JAW$R A)$, 38(4), pp. 967-979, 2002.

[6] Wisconsin Department of Natural Resources. Guidance for Implementing Water Quality Trading in WPDES Permits. Guidance 3800-2013-04. https://dnr.wi.gov/topic/surfacewater/documents/WQT_guidance_Aug_21_2013signed.pdf, 2013 (accessed 26 February 2020).

[7] Woodbury, J. \& Shoemaker, C.A. Stochastic assessment of long-term impacts of phosphorus management options on sustainability with and without climate change. Journal of Water Resources Planning and Management, 139(5), pp. 512-519, 2013.

[8] Ahn, J.M. \& Lyu, S. Assessing future river environments in Seomjin River Basin due to climate change, Journal of Environmental Engineering, 143(5), 04017005, 2017.

[9] Freni, G., Mannina, G., \& Viviani, G. Role of modeling uncertainty in the estimation of climate and socioeconomic impact on river water quality. Journal of Water Resources Planning and Management, 138(5), pp.479-490, 2012.

[10] Johnson, T.E., Butcher, J.B., Parker, A., \& Weaver, C.P. Investigating the sensitivity of U.S. streamflow and water quality to climate change: U.S. EPA Global Change Research Program's 20 watersheds project. Journal of Water Resources Planning and Management, 138(5), pp. 453-464, 2012.

[11] Li, Z., Clark, R.M., Buchberger, S.G., \& Yang, Y.J. Evaluation of climate change impact on drinking water treatment plant operation. Journal of Environmental Engineering, 140(9), A4014005, 2014.

[12] Utah Division of Water Quality. Prioritizing Utah's 303(d) List. https://deq.utah.gov/ legacy/programs/water-quality/watersheds/docs/2016/303d-list-for\%20tmdl-development.pdf, 2016 (accessed 19 February 2020).

[13] Martin, J.L., Ambrose, R.B., \& Wool, T.A. WASP8 Macro Algae-Model Theory and User's Guide. Office of Research and Development, U.S. Environmental Protection Agency, Washington, D.C. 
[14] Abatzoglou, J.T. Development of gridded surface meteorological data for ecological applications and modeling. International Journal of Climatology, 33, pp. 121-131, 2013.

[15] Abatzoglou, J.T. \& Brown, T.J. A Comparison of statistical downscaling methods suited for wildfire applications. International Journal of Climatology, 32, pp. 772-780, 2012.

[16] Forster, K., Hanzer, F., Winter, B., Marke, T., \& Strasser, U. An open-source MEteoroLOgical observation time series DISaggregation Tool (MELODIST v0.1.1). Geoscientific Model Development, 9, pp. 2315-2333, 2016.

[17] Smith, K., Strong, C., \& Wang, S.-Y. Connectivity between historical Great Basin precipitation and Pacific Ocean variability: a CMIP5 model evaluation. Journal of Climate, 28, pp. 6096-6112, 2015.

[18] Stantec Consulting Ltd. Jordan River TMDL: 2010 Qual2Kw Model Calibration- Technical Memo. Utah Department of Environmental Quality, Salt Lake City, UT, 2010.

[19] Mareddy, A.R. Environmental Impact Assessment: Theory and Practice. BSP Books Pvt Ltd, Elsevier, Inc., Cambridge, MA, 2017. 